\title{
Mineralization of Urea-Formaldehyde Fertilizer and Its Availability to Oil Palm Seedling under the Tropical Environment
}

\author{
Napon Klomklao ${ }^{1}$, Somsak Maneepong ${ }^{1} \&$ Potjamarn Suraninpong ${ }^{1}$ \\ ${ }^{1}$ School of Agricultural Technology, Walailak University, Nakhon Si Thammarat, Thailand \\ Correspondence: Somsak Maneepong, School of Agricultural Technology, Walailak University, Nakhon Si \\ Thammarat, Thailand. E-mail: msomsak2012@gmail.com
}

Received: August 6, 2020

Accepted: September 7, $2020 \quad$ Online Published: October 15, 2020

doi:10.5539/jas.v12n11p88

URL: https://doi.org/10.5539/jas.v12n11p88

The research is financed by Walailak University Fund, Thailand.

\begin{abstract}
Easily dissolved fertilizers release nutrient in excess amount to be assimilated by plant roots. Some portions these fertilizers leach out from the root zone and adversely impact the environment. Controlled-release fertilizers are more favorable to reduce fertilizer loss, labor cost, and environmental impact. Urea-formaldehyde (UF) was synthesized by polymerization of urea and $40 \%$ formaldehyde solution using $\mathrm{H}_{3} \mathrm{PO}_{4}$ as a catalyst. Three mole ratios of urea:formaldehyde, namely, 1.0:1.0, 1.5:1.0 and 2.0:1.0 were synthesized. Mineralization of the UF was conducted using eight different mixtures, four different moisture, and four incubation periods. The experiment included soil alone, soil with compost, soil with UF (1.0:1.0), soil with UF (1.5:1.0), soil with UF (2.0:1.0), soil with UF (1.0:1.0) and compost, soil with UF (1.5:1.0) and compost, and soil with UF (2.0:1.0) and compost. Moisture of the mixtures was adjusted to $20 \%, 40 \% 60 \%$ and $80 \%$ water holding capacity (WHC) of the soil. The mixtures were incubated at room temperature for 1, 2, 4 and 8 weeks, the released $\mathrm{NH}_{4}{ }^{+}$and $\mathrm{NO}_{3}{ }^{-}$were extracted by $1 \mathrm{M} \mathrm{KCl}$ and analyzed via a distillation method. Rates of mineralization increased with mole ratio of urea and moisture content of the soil. $\mathrm{N}$ loss increased with the moisture content. The best performance for the compromised condition was a mole ratio less than 1.5:1.0 (urea:formaldehyde) at 60\% WHC. Availability of UF and serpentine-phosphate for oil palm seedlings was conducted using 10 treatments. The experiment consisted of soil without amendment; soil with Multicote; soil with cow manure; soil with cow manure and urea; soil with cow manure and UF (1.0:1.0); soil with cow manure and UF (1.5:1.0); soil with cow manure, $\mathrm{MgHPO}_{4}$ and UF (1.0:1.0); soil with cow manure, $\mathrm{MgHPO}_{4}$ and UF (1.5:1.0); soil with cow manure, serpentine-phosphate and UF (1.0:1.0); and soil with cow manure, serpentine-phosphate and UF (1.5:1.0). All amended soils increased vegetative growth of oil palm seedlings compared with the non-amended soils. Urea and UF increased the $\mathrm{N}$ content in seedling leaves, while Multicote, cow manure, $\mathrm{MgHPO}_{4}$, and serpentine-phosphate increased the $\mathrm{Mg}$ content. The best performance was found in the combination of cow manure, serpentine-phosphate and the UF with mole ratio of 1.0:1.0.
\end{abstract}

Keywords: tropical soil, nitrogen fertilization, controlled-release fertilizer, slow release fertilizer

\section{Introduction}

Urea is the most commonly applied for N-source fertilizers. However, urea is substantially lost through leaching, runoff and volatilization (Yan \& Zheng-yin, 2007; Jantalia, 2012; Yamamoto et al., 2016). The efficiency of N application for cereal production worldwide was estimated to be only 33\% (Raun \& Johnson, 1999). The N losses from agricultural lands contribute to ground water contamination, eutrophication and emission of greenhouse effect gases (Ju et al., 2009; Jantalia et al., 2012; Geng et al., 2015). Loss of urea has been manipulated by various methods such as incorporated with nitrification inhibitors or urease inhibitors, coating with synthetic or natural polymers, and chemically modified urea molecules (Trenkel, 2010; Azeem et al., 2014; Rychter et al., 2016).

Controlled-release fertilizers (CRF) are beneficial to reduce environmental pollution, cost of fertilizer application and improve the efficiency of fertilizer application. Geng et al. (2015) found that application of controlled-release urea at a rate of $70 \%$ of urea produced equal yields of rice and rape seed compared with those 
of the urea. Single application of controlled-release urea as a basal fertilizer could achieve higher yield than split application of urea. Yen and Zheng-yin (2007) found that the N-use efficiency, N-agronomy efficiency and $\mathrm{N}$-physiological efficiency increased by $11.4 \%, 8.32 \mathrm{~kg} \mathrm{~kg}^{-1}$ and $5.17 \mathrm{~kg} \mathrm{~kg}^{-1}$ respectively, for rice when a CRF was applied. Wada, Aragones and Ando (1991) reported that the application of controlled-release urea with only half of ammonium sulfate can produce better yield and increase $\mathrm{N}$ in rice to almost an equal level. Oil palm (Elaeis guineensis) is an economic crop of Southeast Asian countries. It has an average potential yield of 33.2 tons fresh fruit bunches (FFB) ton ${ }^{-1}$ during productive phase, and having the maximum of 40.4 tons FFB ton ${ }^{-1}$ at 10 years after transplanting (Enler, Hoffmann, Fathoni, \& Schwarze, 2016). However, average actual yields stagnated at around 17 to 19 tons FFB ton ${ }^{-1}$. Enler, Hoffmann, Fathoni and Schwarze (2016) found that fertilization during productive phase has strongly affected on yield performance. Donough et al. (2006) reported that oil palm yields in Malaysia increased rapidly after nutrient status in the soil was improved. Therefore, fertilization is a key factor to reduce yield gap of the oil palm. General recommendation of fertilizer rate is larger than 1.2 tons $\mathrm{ha}^{-1}$ to achieve high yield for oil palm having age more than 10 years after transplanting. A large amount of fertilizer loss can be expected in tropical climate, hence CRF should be introduced. Oil palm seedlings have to be cultivated in a nursery around 1 year, and fertilizers have to be applied twice a month. The CRF is also a good alternative for saving labor cost and reducing fertilizer loss. However, information on using of CRFs especially Urea-formaldehyde polymer (UF) for oil palm is still scarce.

UF has been used as a controlled release fertilizer for many decades. However, this polymer is not widely used in Southeast Asia. UF is synthesized by reacting urea $\left(\mathrm{NH}_{2} \mathrm{CONH}_{2}\right)$ with formaldehyde solution by using $\mathrm{H}_{3} \mathrm{PO}_{4}$ or phosphate compounds as catalyst. Paraformaldehyde (short-chain polymerized formaldehyde) may be used instead of formaldehyde solution for reduction of water content in the reaction and product (Yamamoto et al., 2016). Typical UF products contain N between $37 \%$ and $40 \%$ (Alexander \& Helm, 1990). Mineralization of UF depends on mole ratio of urea and formaldehyde, soil $\mathrm{pH}$, soil moisture, temperature and microbial activities. The rate of nitrate production from UF is higher in acidic soil than in neutral soil. The released $\mathrm{N}$ may not sufficient to plants if the soil temperature is below $15^{\circ} \mathrm{C}$ (Basaraba, 1963; Jahns \& Kaltwasser, 2000; Guo, Liu, Liang \& Niu, 2006). UF supplies only N, therefore other nutrients have to be supplied separately. Similar to the UF, serpentine $\left(\mathrm{Mg}_{3} \mathrm{Si}_{2} \mathrm{O}_{5}(\mathrm{OH})_{4}\right)$ has long been used for $\mathrm{Mg}$ source. However, Mg availability of this mineral is very low. The availability can be improved by an acidulation process. Reacting of Serpentine mineral with $\mathrm{H}_{3} \mathrm{PO}_{4}$ produces Serpentine-phosphate, which can be used as a source of both $\mathrm{Mg}$ and $\mathrm{P}$ (Nakamura, Yamazoe, \& Kishimoto, 1956; Hanly, Loganathan, \& Currie, 2005).

The objectives of this study were to examine mineralization of the UF under different mole ratios, soil moisture, and supplement with other sources of nutrients, and respond of oil palm seedling to these combinations.

\section{Materials and Methods}

\subsection{Mineralization of $U F$}

UF was synthesized using 1.0:1.0 (UF01), 1.5:1.0 (UF02) and 2.0:1.0 (UF03) mole ratios of urea: formaldehyde and $2 \mathrm{~mL} \mathrm{~L}^{-1}$ of phosphoric acid $\left(\mathrm{H}_{3} \mathrm{PO}_{4}\right)$ as catalyst. After the reaction was completed, the synthesized UFs were dried in an oven at $80{ }^{\circ} \mathrm{C}$ and ground through a $2 \mathrm{~mm}$ sieve. A sample of surface soil $(0$ to $15 \mathrm{~cm})$ was taken from the Walailak University farm (latitude $8^{\circ} 38.145^{\prime} \mathrm{N}$ longitude $99^{\circ} 54.090^{\prime} \mathrm{E}$ ). The soil was classified as fine, kaolinitic, isohyperthermic Typic Endoaquults. The soil sample was remixed and air-dried, gravel and debris were removed. The sample was ground and sieved through a $2 \mathrm{~mm}$ screen for the chemical analysis. Soil $\mathrm{pH}$ and electrical conductivity (EC) were measured using 1:2.5 and 1:5 of soil: water ratios, respectively. The EC at saturation point (ECe) was estimated by multiplying the EC with 6 (Shaw, 1999). Soil organic matter was analyzed using the Walkley and Black method. Exchangeable $\mathrm{K}, \mathrm{Ca}$ and $\mathrm{Mg}$ were analyzed via atomic absorption spectrophotometry (Jones, 2001, 2003). Available P was analyzed using the molybdenum blue method (Jones, 2001, 2003). Available S was analyzed using a turbidimetric method (Jones, 2001, 2003). The microelements, namely, $\mathrm{Fe}, \mathrm{Mn}, \mathrm{Zn}$ and $\mathrm{Cu}$ were analyzed via atomic absorption spectrophotometry (Jones, 2001, 2003). A factorial design with 8 main-plots and $4 \times 4$ sub-plots was employed (Table 1). The soil (20 g) was placed into a $250 \mathrm{~mL}$ erlenmeyer flask, mixed with or without $2 \mathrm{~g}$ of chicken compost $(2.32 \%$ total $\mathrm{N}, 4.86 \%$ $\mathrm{P}_{2} \mathrm{O}_{5}, 2.90 \% \mathrm{~K}_{2} \mathrm{O}, 3.37 \% \mathrm{Ca}, 1.08 \% \mathrm{Mg}$ ), and mixed with or without $0.2 \mathrm{~g}$ of the UFs. Water was added into the flasks for adjusting soil moisture to $20 \%, 40 \%, 60 \%$ and $80 \%$ of the water holding capacity (WHC). The mixtures were made to stand at room temperature for 1,2, 4 or 8 weeks. At the end of the incubation period, 50 $\mathrm{mL}$ of $1 \mathrm{M} \mathrm{KCl}$ was added, and the mixture was shaken for 30 minutes by a reciprocal shaker at $120 \mathrm{rpm}$. The suspension was filtered and leached with deionized water, until $100 \mathrm{~mL}$ of solution was obtained. The solution was analyzed for ammonium $\left(\mathrm{NH}_{4}^{+}\right)$and nitrate $\left(\mathrm{NO}_{3}{ }^{-}\right)$by a distillation method (Mulvaney, 1996). Statistical analysis was performed using Duncan's Multiple Range test (DMRT). 
Table 1. Arrangement of the mineralization experiment, each main-plot was split into $20 \%, 40 \%, 60 \%$ and $80 \%$ WHC, and incubation for 1, 2, 4 and 8 weeks

\begin{tabular}{ll}
\hline Treatments & Description \\
\hline T1 & Soil $(20 \mathrm{~g})$ \\
T2 & Soil $(20 \mathrm{~g})+\operatorname{compost}(2 \mathrm{~g})$ \\
T3 & Soil $(20 \mathrm{~g})+\operatorname{UF0} 1(0.2 \mathrm{~g})$ \\
T4 & Soil $(20 \mathrm{~g})+\operatorname{UF02}(0.2 \mathrm{~g})$ \\
T5 & Soil $(20 \mathrm{~g})+\operatorname{UF03}(0.2 \mathrm{~g})$ \\
T6 & Soil $(20 \mathrm{~g})+\operatorname{compost}(2 \mathrm{~g})+\mathrm{UF0}(0.2 \mathrm{~g})$ \\
T7 & Soil $(20 \mathrm{~g})+\operatorname{compost}(2 \mathrm{~g})+\operatorname{UF02}(0.2 \mathrm{~g})$ \\
T8 & Soil $(20 \mathrm{~g})+\operatorname{compost}(2 \mathrm{~g})+\operatorname{UF03}(0.2 \mathrm{~g})$ \\
\hline
\end{tabular}

\subsection{Pot Experiment}

A soil sample was taken from the same place of the previous experiment (section 2.1). A completely randomized design (CRD) with 10 treatments and 5 replications was employed. A total of $8 \mathrm{~kg}$ of the air-dried soil was placed into a plastic pot with a diameter of $25 \mathrm{~cm}$. Deionized water was added to increase the soil moisture to $65 \%$ of WHC. Fertilizers and cow manure were mixed with the soil separately to prepare 10 treatments: soil; soil with Multicote (19-10-13+1.5MgO, Haifa CRF fertilizer); soil with cow manure; soil with cow manure and urea; soil with cow manure and UF01; soil with cow manure and UF02; soil with cow manure, UF01 and $\mathrm{MgHPO}_{4}$; soil with cow manure, UF02 and $\mathrm{MgHPO}_{4}$; soil with cow manure, UF01 and Serpentine-phosphate; soil with cow manure, UF02 and Serpentine-phosphate (Table 2). Oil palm seedlings (90 days after germination) were transplanted into treatment pots (one seedling per pot). The experiment was carried out in a plastic-sheet covered house for 38 weeks. At the end of experiment; plant height was measured, number of fully expanded leaves were counted, and upper-ground of the seedlings were cut and their dry weight were measured. The leaf samples were collected, gently wiped with a clean cloth, and packed into marked paper bags. The samples were dried at $70{ }^{\circ} \mathrm{C}$ for 72 hours, ground and passed through a $1 \mathrm{~mm}$ sieve and then kept in plastic container to analyze the macronutrient and micronutrient elements. Prior to the analysis, the samples were re-dried at $70{ }^{\circ} \mathrm{C}$ for 2 hours and cooled down in a desiccator. Total-N was analyzed using the Kjeldahl method (Jones, 2001), A portion of the sample was digested by $\mathrm{HNO}_{3}: \mathrm{HClO}_{4}(2: 1)$ mixture. The $\mathrm{P}$ concentration was analyzed using the Vanadomolybdate method, the $\mathrm{K}$ concentration using flame emission spectrophotometry, and $\mathrm{Ca}, \mathrm{Mg}$ concentrations using atomic absorption spectrophotometry (Jones, 2001). Statistical analysis was performed using Duncan's Multiple Range test.

Table 2. Arrangement of the pot experiment, each treatment consisted of 5 replications

\begin{tabular}{|c|c|}
\hline Treatments & Description \\
\hline T1 & Soil $(8 \mathrm{~kg})$ \\
\hline $\mathrm{T} 2$ & Soil $(8 \mathrm{~kg})+$ Multicote $(10.3 \mathrm{~g})$ \\
\hline $\mathrm{T} 3$ & Soil $(8 \mathrm{~kg})+$ cow manure $(1 \mathrm{~kg})$ \\
\hline $\mathrm{T} 4$ & Soil $(8 \mathrm{~kg})+$ cow manure $(1 \mathrm{~kg})+$ Urea $(4.3 \mathrm{~g})$ \\
\hline T5 & Soil $(8 \mathrm{~kg})+$ cow manure $(1 \mathrm{~kg})+\mathrm{UF0} 01(5.6 \mathrm{~g})$ \\
\hline T6 & Soil $(8 \mathrm{~kg})+$ cow manure $(1 \mathrm{~kg})+\mathrm{UF0} 2(5.6 \mathrm{~g})$ \\
\hline $\mathrm{T} 7$ & Soil $(8 \mathrm{~kg})+$ cow manure $(1 \mathrm{~kg})+\mathrm{UF} 01(5.6 \mathrm{~g})+\mathrm{MgHPO}_{4}(4.6 \mathrm{~g})$ \\
\hline $\mathrm{T} 8$ & Soil $(8 \mathrm{~kg})+$ cow manure $(1 \mathrm{~kg})+\mathrm{UF} 02(5.6 \mathrm{~g})+\mathrm{MgHPO}_{4}(4.6 \mathrm{~g})$ \\
\hline T9 & Soil $(8 \mathrm{~kg})+$ cow manure $(1 \mathrm{~kg})+\mathrm{UF0} 1(5.6 \mathrm{~g})+$ Serpentine-P $(4.6 \mathrm{~g})$ \\
\hline $\mathrm{T} 10$ & Soil $(8 \mathrm{~kg})+$ cow manure $(1 \mathrm{~kg})+\mathrm{UF0} 2(5.6 \mathrm{~g})+$ Serpentine-P $(4.6 \mathrm{~g})$ \\
\hline
\end{tabular}

\section{Results and Discussion}

\subsection{Soil Chemical Properties}

The chemical properties of the soil sample are listed in Table 3. The soil was acid and non-saline. The soil also contained low organic matter and low concentrations of $\mathrm{P}, \mathrm{K}, \mathrm{Ca}, \mathrm{Mg}, \mathrm{S}$ and $\mathrm{Cu}$. In addition, extractable $\mathrm{Fe}$ and $\mathrm{Mn}$ were high, and $\mathrm{Zn}$ was in a medium range (Jones, 2001, 2003). The properties indicated that acidity and salinity of the soil do not inhibit microbial activities. However, multiple nutrients have to be amended to improve microbial activities and plant growth. 
Table 3. Chemical properties and nutrient concentrations of the soil sample taken from the depth of 0 to $15 \mathrm{~cm}$

\begin{tabular}{lll}
\hline Property & Unit & Value (mean \pm SD) \\
\hline $\mathrm{pH}(1: 2.5$ in water) & & $5.42 \pm 0.01$ \\
$\mathrm{ECe}$ (Saturation) & $\mathrm{mS} \mathrm{cm}^{-1}$ & $0.51 \pm 0.03$ \\
$\mathrm{OM}$ (Walkley \& Black) & $\mathrm{g} \mathrm{kg}^{-1}$ & $17.8 \pm 0.5$ \\
$\mathrm{P}($ BrayII) & $\mathrm{mg} \mathrm{kg}^{-1}$ & $11.5 \pm 0.4$ \\
$\mathrm{~S}\left(0.01 \mathrm{M} \mathrm{KH}_{2} \mathrm{PO}_{4}\right)$ & $\mathrm{mg} \mathrm{kg}^{-1}$ & $0.58 \pm 0.05$ \\
$\mathrm{~K}\left(1 \mathrm{M} \mathrm{NH}_{4} \mathrm{OAc} \mathrm{pH} \mathrm{7)}\right.$ & $\mathrm{mg} \mathrm{kg}^{-1}$ & $61.7 \pm 0.1$ \\
$\mathrm{Mg}\left(1 \mathrm{M} \mathrm{NH}_{4} \mathrm{OAc} \mathrm{pH} \mathrm{7)}\right.$ & $\mathrm{mg} \mathrm{kg}^{-1}$ & $41.7 \pm 0.9$ \\
$\mathrm{Ca}\left(1 \mathrm{M} \mathrm{NH} \mathrm{OAc} \mathrm{pH}_{4} \mathrm{O}\right)$ & $\mathrm{mg} \mathrm{kg}^{-1}$ & $423 \pm 4$ \\
$\mathrm{Fe}(\mathrm{DTPA}$ extractable) & $\mathrm{mg} \mathrm{kg}^{-1}$ & $85 \pm 4$ \\
$\mathrm{Mn}(\mathrm{DTPA}$ extractable) & $\mathrm{mg} \mathrm{kg}^{-1}$ & $30.8 \pm 0.4$ \\
$\mathrm{Zn}($ DTPA extractable) & $\mathrm{mg} \mathrm{kg}^{-1}$ & $1.13 \pm 0.17$ \\
$\mathrm{Cu}$ (DTPA extractable) & $\mathrm{mg} \mathrm{kg}^{-1}$ & $0.29 \pm 0.04$ \\
\hline
\end{tabular}

\subsection{Mineralization of UF}

The soil sample released a small amount of $\mathrm{N}$ from the mineralization of the organic matter in the soil. The soil contained $17.8 \mathrm{~g} \mathrm{~kg}^{-1}$ of organic matter (approximately $1 \mathrm{~g} \mathrm{~kg}^{-1}$ of nitrogen), resulting in the mineralization of $\mathrm{N}$. The soil nitrogen was mineralized to $\mathrm{NH}_{4}{ }^{+}$and then partially transformed to $\mathrm{NO}_{3}{ }^{-}$. The total amounts of $\mathrm{NH}_{4}{ }^{+}$ and $\mathrm{NO}_{3}{ }^{-}$increased with prolonged incubation periods, that is from $30 \pm 3 \mathrm{mg}-\mathrm{N} \mathrm{kg}^{-1}$ on the first week to $80 \pm 13$ mg- $\mathrm{N} \mathrm{kg}^{-1}$ on the eighth week. $\mathrm{NH}_{4}^{+}$was dominant on the first week, but the ratios of $\mathrm{NH}_{4}{ }^{+} / \mathrm{NO}_{3}{ }^{-}$declined afterward. Nitrification at higher moisture content progressed faster than at lower level. On the eighth week, $49 \%$, $60 \%, 88 \%$ and $93 \%$ of inorganic $\mathrm{N}$ presented in $\mathrm{NO}_{3}{ }^{-}$form at $20 \%, 40 \%, 60 \%$ and $80 \%$ WHC, respectively (Figure 1).

Soil amendment with compost released more $\mathrm{NH}_{4}{ }^{+}$and $\mathrm{NO}_{3}{ }^{-}$than the soil alone (Figure 1). However, the total amounts slightly increased with prolonged incubation periods. The results indicated that most of the mineralizable $\mathrm{N}$ from the compost was released on the first week. The ratios of $\mathrm{NO}_{3}{ }^{-}$increased with prolonged incubation period and increased moisture content. On the eighth week, $\mathrm{NO}_{3}{ }^{-}$was dominated for $40 \%, 60 \%$ and $80 \% \mathrm{WHC}$, whereas $\mathrm{NH}_{4}{ }^{+}$was dominated at $20 \% \mathrm{WHC}$. The results indicated that nitrification progress faster under higher moisture condition.
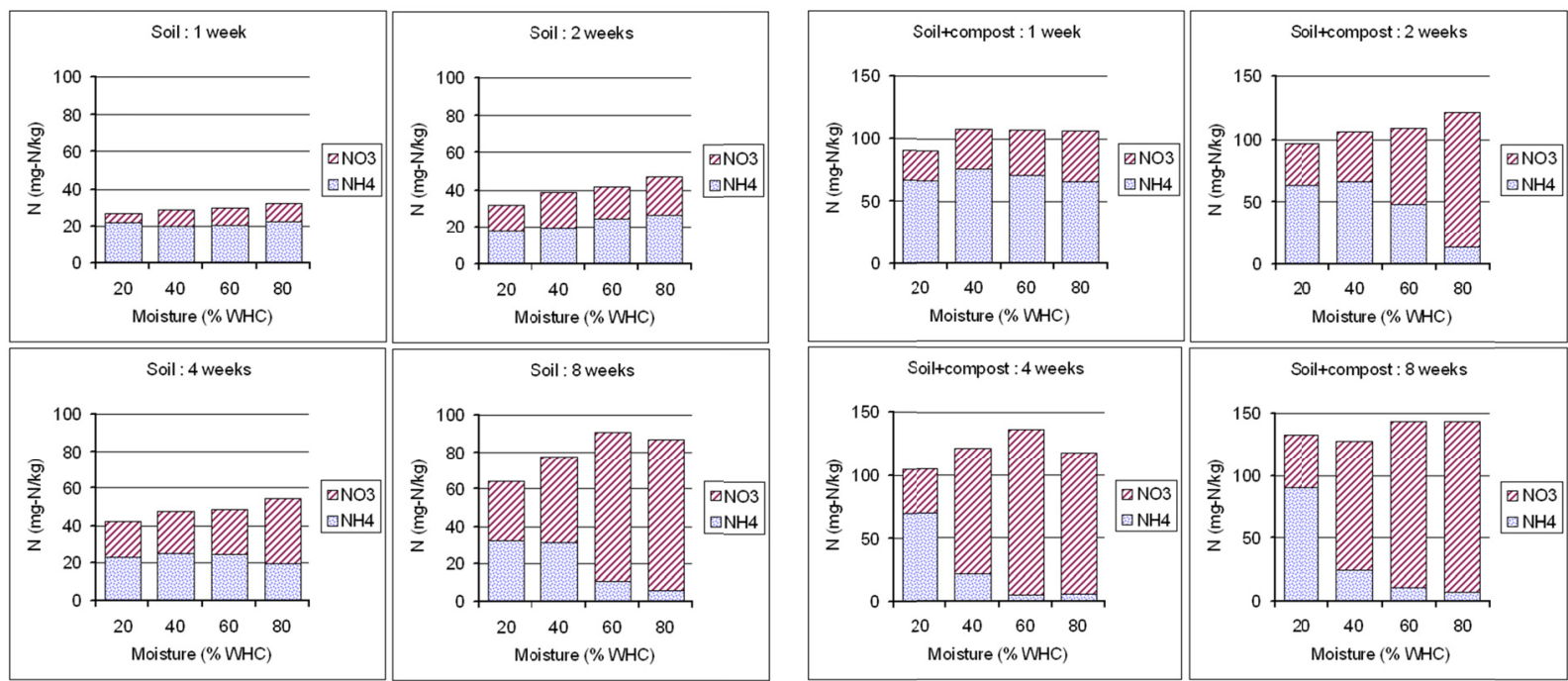

Figure 1. Releasing of $\mathrm{NH}_{4}{ }^{+}$and $\mathrm{NO}_{3}{ }^{-}$from the unamended soil (left) and soil amended with compost (right) at different moisture contents and incubation periods

The release of $\mathrm{NH}_{4}{ }^{+}$and $\mathrm{NO}_{3}{ }_{3}^{-}$from the soil amended with UF01 was slower than that of the soil with compost. The soil with UF01 released 49, 59, 54, and $74 \mathrm{mg}-\mathrm{N} \mathrm{kg}^{-1}$ of $\mathrm{NH}_{4}{ }^{+}$and $\mathrm{NO}_{3}{ }^{-}$at $20 \%, 40 \% 60 \%$ and $80 \% \mathrm{WHC}$, respectively on the first week; whereas the soil with compost released 50,108, 107, and $106 \mathrm{mg}-\mathrm{N} \mathrm{kg}^{-1}$ on the 
same condition (Figure 2). The amounts of $\mathrm{NH}_{4}^{+}$and $\mathrm{NO}_{3}^{-}$from the UF01 gradually increased with the incubation period, but no increase was observed from the mineralization of compost after 2 weeks (Figure 1). The release of $\mathrm{NH}_{4}{ }^{+}$and $\mathrm{NO}_{3}{ }^{-}$tended to increase with moisture content. $\mathrm{NH}_{4}{ }^{+}$and $\mathrm{NO}_{3}{ }^{-}$were released only $92 \pm 4$ $\mathrm{mg}-\mathrm{N} \mathrm{kg}^{-1}$ at $20 \% \mathrm{WHC}$, whereas these compounds released as much as $200 \pm 2 \mathrm{mg}-\mathrm{N} \mathrm{kg}^{-1}$ at $80 \%$ WHC on the eighth week. The results indicated that mineralization rate and the nitrification progressed of UF01 was slower than that of the soil with compost. The UF01 is a source of $\mathrm{N}$ alone; therefore, microbial growth is limited due to lack of other nutrients.
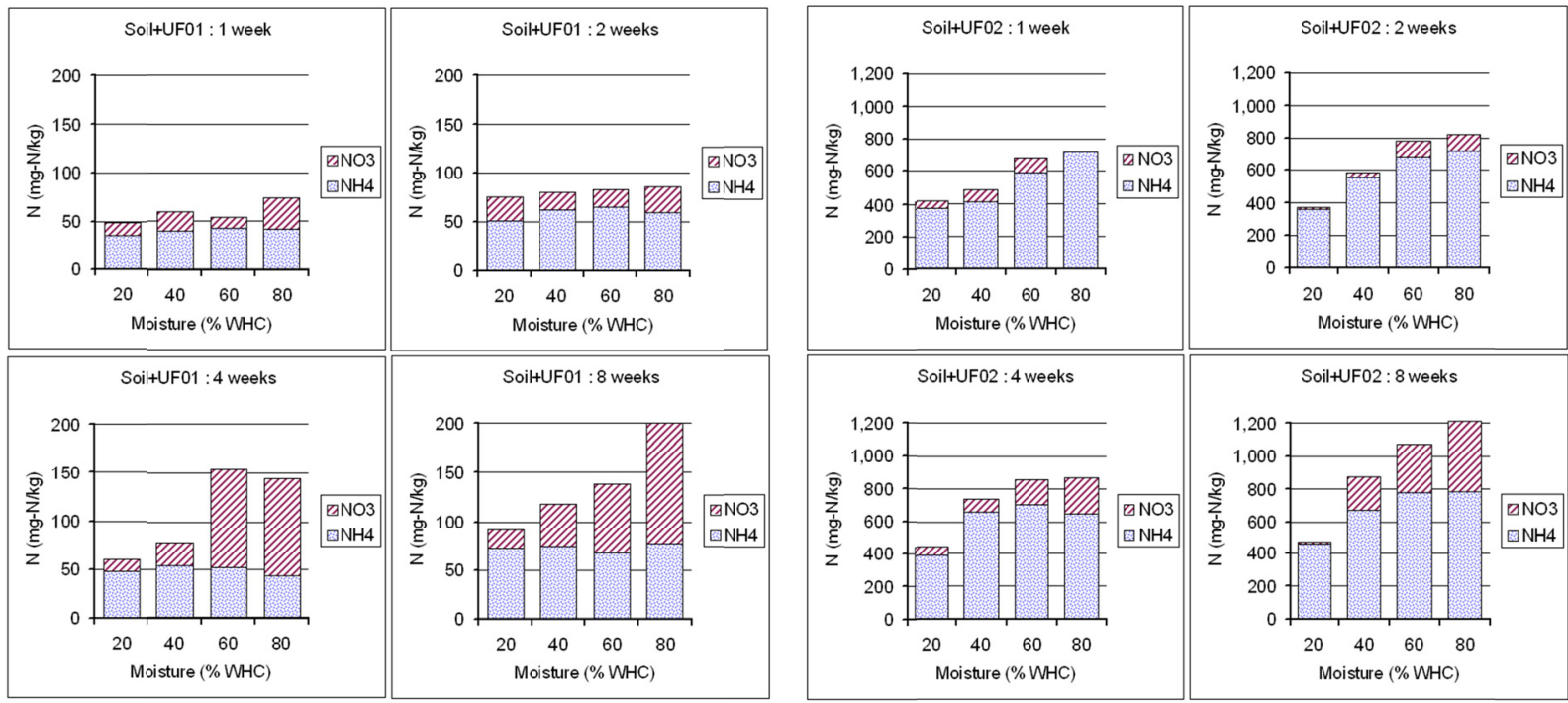

Figure 2. $\mathrm{NH}_{4}{ }^{+}$and $\mathrm{NO}_{3}{ }^{-}$released from the soil amended with UF01 (left) and soil with UF02 (right) at different moisture contents and incubation periods

UF02 released $\mathrm{NH}_{4}{ }^{+}$and $\mathrm{NO}_{3}{ }^{-}$faster than UF01 (Figure 2). The amount of released $\mathrm{NH}_{4}{ }^{+}$and $\mathrm{NO}_{3}{ }^{-}$was $712 \pm 82$ $\mathrm{mg}-\mathrm{N} \mathrm{kg}{ }^{-1}$ on the first week at $80 \%$ WHC, whereas $74 \pm 4 \mathrm{mg}_{-} \mathrm{N} \mathrm{kg}^{-1}$ was released from UF01. Higher mole ratio of urea-to-formaldehyde produced UF polymer that can be more easily mineralized. The ratios of $\mathrm{NH}_{4}^{+} \mathrm{were}^{-}$ higher than those of $\mathrm{NO}_{3}{ }^{-}$for all moisture content. The results indicated that the release rate of $\mathrm{N}$ was faster than nitrification. Mineralization of the UF02 occurred rapidly and may be too fast to be uptake by plants.

The release of $\mathrm{NH}_{4}{ }^{+}$and $\mathrm{NO}_{3}{ }^{-}$from the soil amendment with UF03 increased with moisture content on the first and second weeks but tended to decline afterward, especially at $80 \%$ WHC (Figure 3). The result indicated that denitrification occurred at high moisture content and extended incubation period. Most of the released $\mathrm{N}$ existed in $\mathrm{NH}_{4}^{+}$form for all moisture contents and incubation periods. Similar to UF02, the release rate of $\mathrm{N}$ was faster than nitrification. The UF03 may not suitable for using as a controlled release fertilizer. 

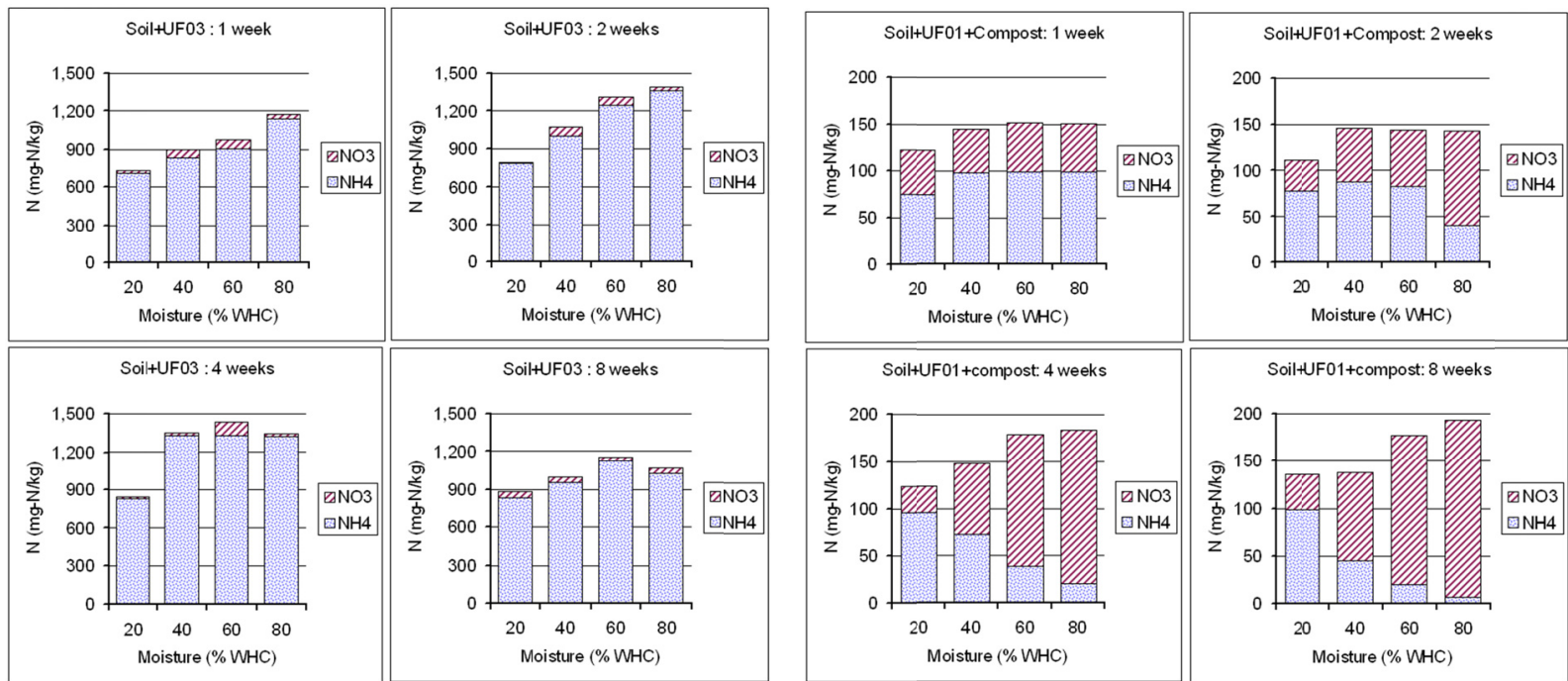

Figure 3. $\mathrm{NH}_{4}{ }^{+}$and $\mathrm{NO}_{3}{ }^{-}$released from soil amended with UF03 (left) and soil with UF01 and compost (right) at different moisture contents and incubation periods

The mixture of UF01 and compost released a larger amount of N than UF01 alone, because a large portion of N originated from the compost. The ratios of $\mathrm{NO}_{3}{ }^{-}$increased with prolonged incubation period and moisture content. On the eighth week, the $\mathrm{NO}_{3}{ }^{-}$was released by $27.6 \pm 4.0 \%, 66.3 \pm 7.3 \%, 88.9 \pm 3.4 \%$ and $96.4 \pm 0.8 \%$ at $20 \%, 40 \%, 60 \%$ and $80 \%$ WHC, respectively (Figure 3). Addition of compost enhanced the nitrification in the case of UF01. The mixtures of UF02 and UF03 with compost released N similar to that of sole UF02 or sole UF03, and most of the $\mathrm{N}$ was in $\mathrm{NH}_{4}{ }^{+}$form (Figure 4). Addition of compost did not significantly accelerate the nitrification in the cases of UF02 and UF03. This phenomenon may due to the very fast release of $\mathrm{NH}_{4}{ }^{+}$and high concentration of $\mathrm{NH}_{4}^{+}$accumulated in the soil.
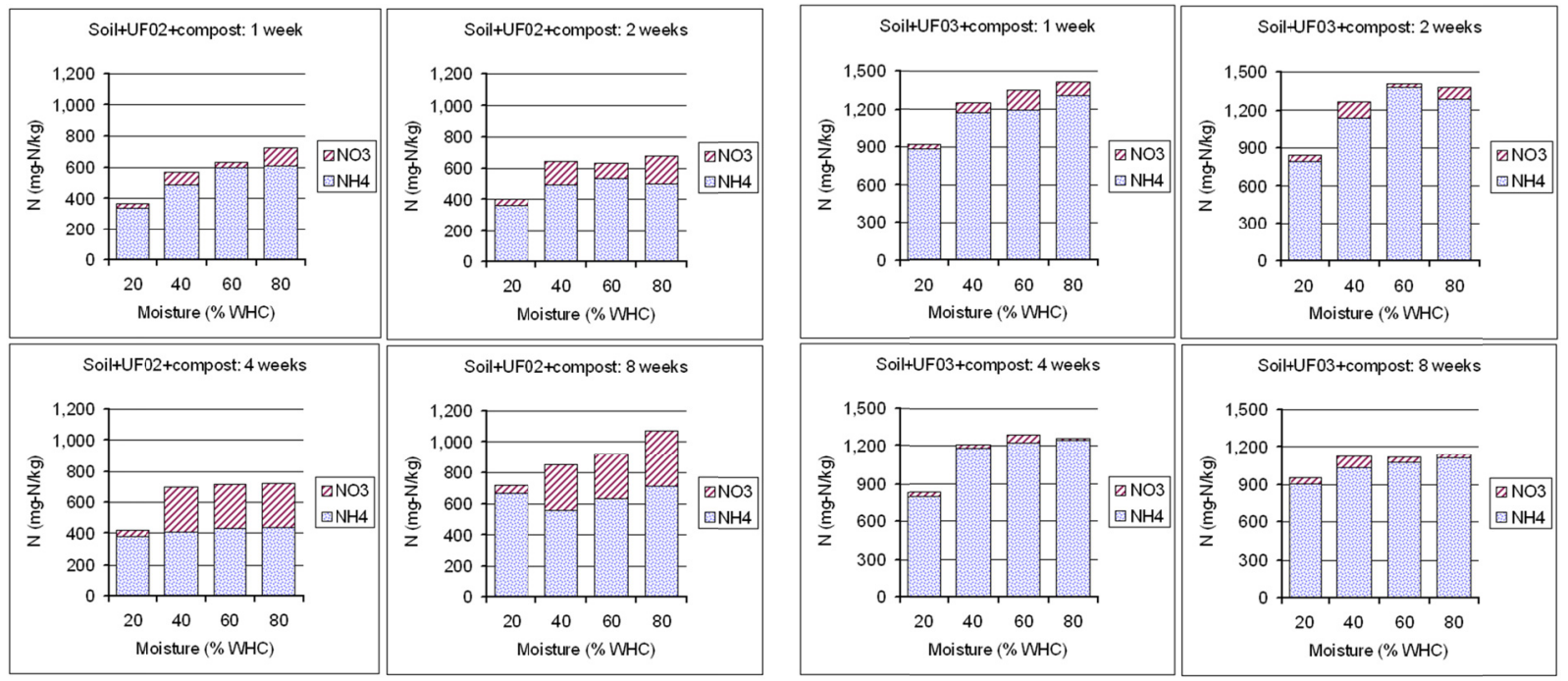

Figure 4. $\mathrm{NH}_{4}{ }^{+}$and $\mathrm{NO}_{3}{ }^{-}$released from the soil amended with UF02 and compost (left) and soil with UF03 and compost (right) at different moisture contents and incubation periods

\subsection{Pot Experiment}

Growth indexes were measured at the end of experiment. Soil amended with cow manure, UF01 and serpentine-phosphate (T9) showed the highest plant height, number of leaves and shoot biomass (Figure 5). The results indicated that the oil palm seedling required additional $\mathrm{N}, \mathrm{P}$ and $\mathrm{Mg}$ for the experimental soil. Multicote (T2) showed better performance than the soil alone. The amount of Multicote may be too little or its release rate 
of nutrient may be slower than plant assimilation. Cow manure (T3) also substantially affected on the growth performance. Urea, UF01 and UF02 did not show significant differences in plant height, number of leaves and shoot biomass (T4, T5 and T6). This phenomenon may be due to the fact that the nursery period was not long. Therefore, the release rate of $\mathrm{N}$ did not affect the seedling growth. UF02 tended to show better results than the UF01 when the former was applied in combination with $\mathrm{MgHPO}_{4}$ (T7 and T8). UF01 showed markedly better results than UF02, when the former was applied in combination with serpentine phosphate (T8 and T9).
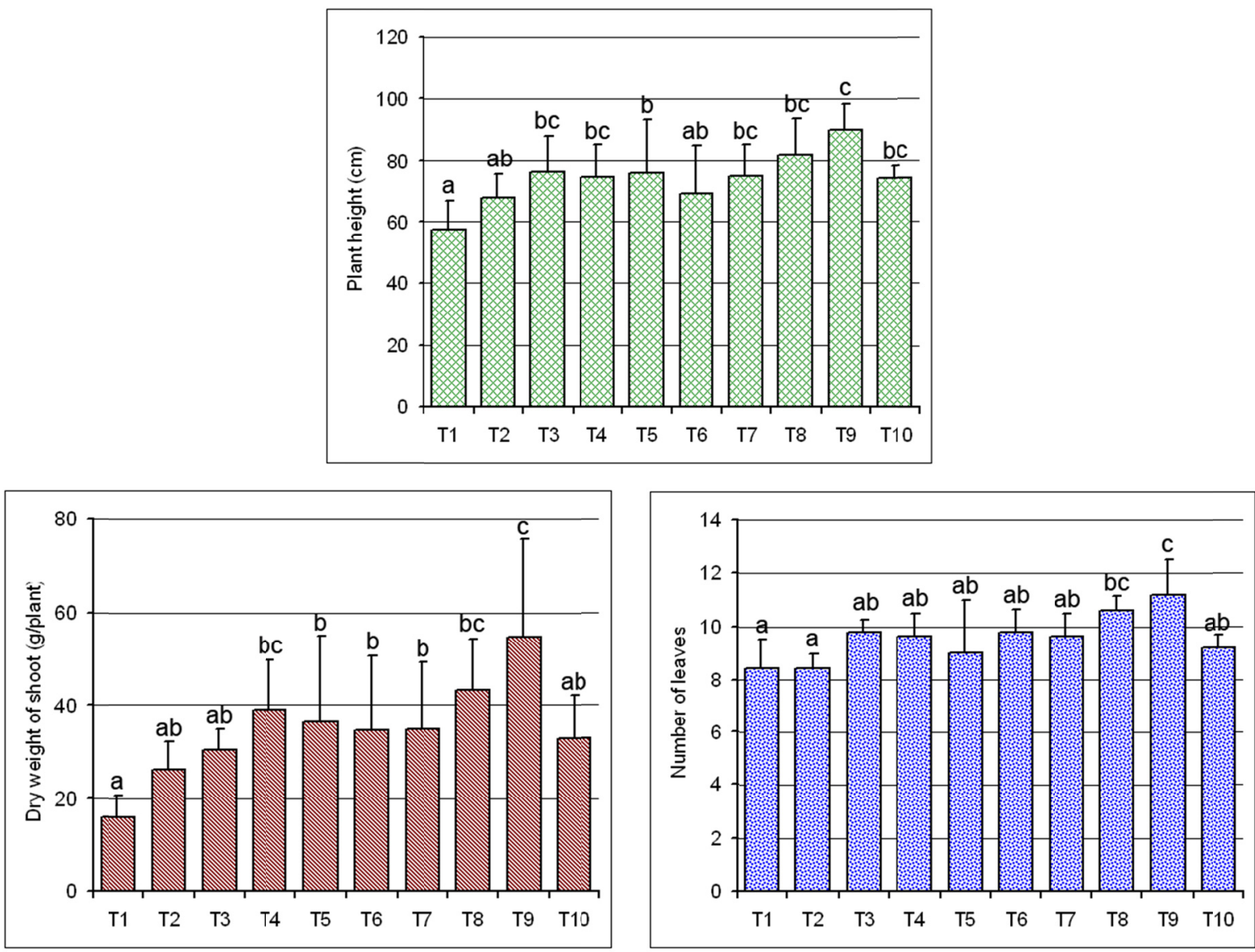

Figure 5. Plant height, number of leaves, and shoot biomass of oil palm seedling at 38 weeks after transplanting Note. Difference letters within the columns indicate significant difference $(\mathrm{P} \leq 0.05)$.

\subsection{Nutrient Concentrations in the Seedling Leaves}

Leaf samples of the oil palm seedlings were collected at the end of experiment and analyzed for $\mathrm{N}, \mathrm{P}$ and $\mathrm{Mg}$. $\mathrm{N}$ in the leaves of the seedling grown in the soil without amendment (T1) was significantly lower than the those treated with $\mathrm{N}$ sources (Figure 6). This result indicated that $\mathrm{N}$ in the soil was not sufficient for seedling growth. Sufficient N concentration of $2.4 \%$ to $3.0 \%$ is suggested for oil palm (von Uexkull and Fairhurst, 1991). No significant differences in $\mathrm{N}$ were found in the leaves of the seedling grown in soils amended with urea, UF0I and UF02 (T4, T5 and T6). The results indicated that the rates of released $\mathrm{N}$ did not affect ability of plant uptake. Addition of $\mathrm{P}$ and $\mathrm{Mg}$ did not significantly affect $\mathrm{N}$ in the seedling leaves (T7, T8, T9 and T10). $\mathrm{N}$ is a translocated nutrient. Although, soil concentration declined, the sufficient level is maintained by relocation from the old leaves to the young leaves.

The concentration of available $\mathrm{P}$ in the soil was $11.5 \mathrm{mg}-\mathrm{P} \mathrm{kg}^{-1}$, which was generally considered as low level (Jones, 2001, 2003). Therefore, addition of $\mathrm{P}$ should exhibit a positive effect on plant growth. The $\mathrm{P}$ concentration in the leaves of the seedling grown in the soil without amendment (T1) was significantly lower than those in the other treatments (Figure 6). The result agreed well with the soil analysis. Sufficient leaf-P concentration of $0.15 \%$ to $0.19 \%$ is suggested for oil palm (von Uexkull and Fairhurst, 1991). The addition of 
Multicote tended to increase P, but did not reach the sufficient level. This phenomenon may due to the fact that the added amount was not sufficient or its release rate was too slow for the oil palm seedling. Addition of $\mathrm{MgHPO}_{4}$ and serpentine-phosphate did not significantly increase the $\mathrm{P}$ concentrations more than that when cow manure was added. The results indicated that oil palm did not uptake P higher than the sufficient level. The highest P concentration was found in the seedling grown in the soil amended with cow manure and UF01 (T5). Slow N release of the UF01 tended to enhance P uptake.
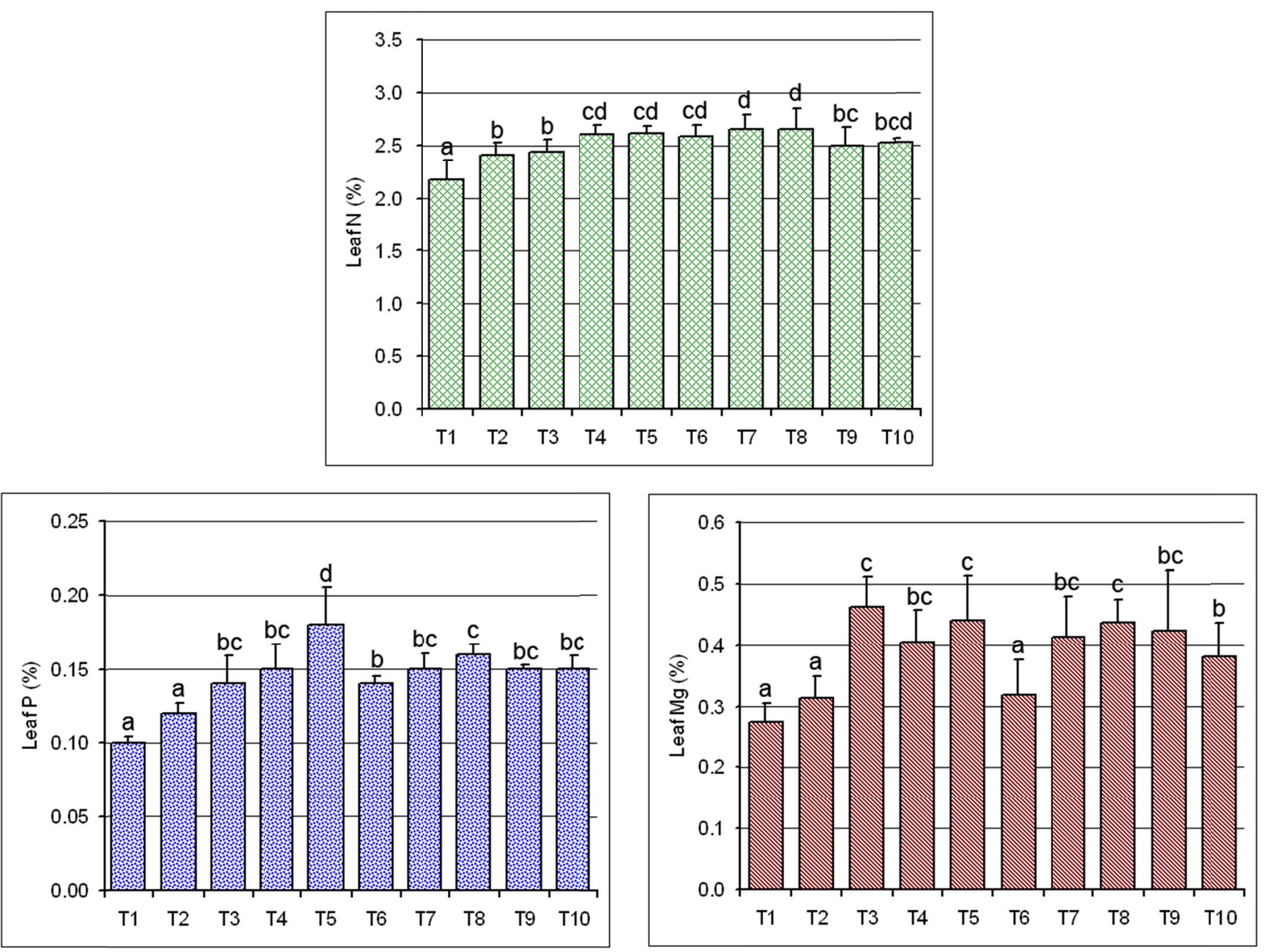

Figure 6. N, P and Mg contents in the leaves of oil palm seedling at the end of experiment

Note. Difference letters within the columns indicate significant difference $(\mathrm{P} \leq 0.05)$.

The concentration of extractable $\mathrm{Mg}$ in the soil was $41.7 \mathrm{mg} \mathrm{kg}^{-1}$, which was generally considered as very low (Jones, 2001, 2003). Therefore, the amount of Mg in the soil was not sufficient for seedling growth. Plants require 1 mole of $\mathrm{Mg}$ for every 4 moles of $\mathrm{N}$ for chlorophyll synthesis. Therefore, $\mathrm{N}$ and $\mathrm{Mg}$ should be supplied in balance of mole ratio. $\mathrm{Mg}$ in the leaves of the seedling grown in the soil without amendment (T1) was significantly lower than those in the other treatments, except in T6 (Figure 6). Von Uexkull and Fairhurst (1991) suggested a sufficient range of $0.30 \%$ to $0.45 \%$ for $\mathrm{Mg}$ in oil palm leaves. Mean values of all treatments, except $\mathrm{T} 1$, were above the lower limit. Addition of Multicote tended to increase Mg to the lower margin. The addition of $\mathrm{MgHPO}_{4}$ or serpentine-phosphate (T7, T8, T9 and T10) did not increase $\mathrm{Mg}$ concentration more than that with cow manure. Therefore, supplying Mg from the manure was sufficient for the seedling.

\section{Conclusion}

Mineralization of UF fertilizer depends on its reacted mole ratio, soil moisture and microbial substrate. A lower mole ratio of urea to formaldehyde retarded the rate of mineralization. Higher soil moisture and addition of compost enhanced the rate of mineralization. UF firstly mineralized into $\mathrm{NH}_{4}^{+}$and consequently transformed to $\mathrm{NO}_{3}{ }^{-}$. Excessive moisture in the soil enhanced the transformation rate. However, a part of $\mathrm{N}$ tended to loss from the soil. The mole ratio less than 1.5:1.0 (urea: formaldehyde) and soil moisture between 40 to $60 \% \mathrm{WHC}$ are 
recommended. A low fertile soil amended with cow manure, UF01 and serpentine-phosphate showed the best combination as media of oil palm seedling during nursery phase.

\section{References}

Alexander, A., \& Helm, H. U. (1990). Ureaform as a slow release fertilizer: A review. Zeitschrift für Pflanzenernährung und Bodenkunde, 153(4), 249-255. https://doi.org/10.1002/jpln.19901530410

Azeem B., KuShaari, K., Man, Z. B., Basit, A., \& Thanh, T. H. (2014). Review on materials \& methods to produce controlled release coated urea fertilizer. Journal of Controlled Release, 181, 11-21. https://doi.org/ 10.1016/j.jconrel.2014.02.020

Basaraba, J. (1963). Mineralization of urea-formaldehyde compounds at different $\mathrm{pH}$ levels and temperatures. Can. J. Soil Sci., 44, 131-136. https://doi.org/10.4141/cjss64-016

Donough, C. R., Witt, C., Fairhurst, T. H., Griffiths, W., \& Gfroerer-Kerstan, A. (2006). Concept and implementation of best management practice for maximum economic yield in oil palm plantations. Paper presented at the Fifth International Planters Conference 2006, June 26-27, 2006, Putrajaya Marriot Hotel, Putrajaya, Malaysia.

Enler, M., Hoffmann, M. P., Fathoni, Z., \& Schwarze, S. (2016). Exploring yield gaps in smallholder oil palm production systems in eastern Sumatra, Indonesia. Agricultural Systems, 146, 111-119. https://doi.org/ 10.1016/j.agsy.2016.04.007

Geng, J., Sun, Y., Zhang, M., Li, C., Yang, Y., Liu, Z., \& Li, S. (2015). Long-term effects of controlled release urea application on crop yields and soil fertility under rice-oilseed rape rotation system. Field Crops Research, 184, 65-73. https://doi.org/10.1016/j.fcr.2015.09.003

Guo, M., Liu, M., Liang, R., \& Niu, A. (2006). Granular urea-formaldehyde slow-release fertilizer with superabsorbent and moisture preservation. Applied Polymer Science, 99, 3232-3235. https://doi.org/ 10.1002/app.22892

Hanly, J. A., Loganathan, P., \& Currie, L. D. (2005). Effect of serpentine rock and its acidulated products as magnesium fertilisers for pastule, compared with magnesium oxide and Epsom salts, on a Pumice Soil. 1. Dry matter yield and magnesium uptake. New Zealand Journal of Agricultural Research, 48(4), 451-460. https://doi.org/10.1080/00288233.2005.9513679

Jahns, T., \& Kaltwasser, H. (2000). Mechanism of microbial degradation of slow-release fertilizers. Journal Polymers of the Environment, 8(1), 11-16. https://doi.org/10.1023/A:1010116027139

Jantalia, C. P., Halvorson, A.D., Follett, R. F., Alves, B. J. R., Polidoro, J. C., \& Urquiaga, S. (2012). Nitrogen source effects on ammonia volatilization as measured with semi-static chambers. Agronomy Journal, 104(6), 1595-1603. https://doi.org/10.2134/agronj2012.0210

Jones, J. B. (2001). Laboratory guide for conducting soil tests and plant analysis. Washington: CRC Press. https://doi.org/10.1201/9781420025293

Jones, J. B. (2003). Agronomic handbook: Management of crops, soils and their fertility. New York: CRC Press. https://doi.org/10.1201/9781420041507

Ju, X. T., Xing, G. X., Chen, X. P., Zhang, S. L., Zhang, L. J., Liu, X. J., \& Zhang, F. S. (2009). Reducing environmental risk by improving $\mathrm{N}$ management in intensive Chinese agricultural systems. Proceedings of the National Academy of Sciences, 106(9), 3041-3046. https://doi.org/10.1073/pnas.0813417106

Mulvaney, R. L. (1996). Nitrogen - Inorganic forms. In D. L. Spark, A. L. Page, P. A. Helmke, R. H. Loeppert, P. N. Soltanpour, M. A. Tabatabai, ... M. E. Sumner (Eds.), Methods of Soil Analysis Part 3 Chemical methods (pp. 1123-1184). Madison: Soil Science Society of America. https://doi.org/10.2136/sssabookser5.3.c38

Nakamura, T., Yamazoe, F., \& Kishimoto, K. (1956). Reaction between superphosphate and serpentine (part 1) effect of free water and phosphoric acid on conversion to available magnesium. Soil Science and Plant Nutrition, 2(1), 49-52. https://doi.org/10.1080/00380768.1956.10431856

Raun, W. R., \& Johnson, G. V. (1999). Improving nitrogen use efficiency for cereal production. Agronomy Journal, 91(3), 357-363. https://doi.org/10.2134/agronj1999.00021962009100030001x

Rychter, P., Kot, M., Bajer, K., Rogacz, D., Siskova, A., \& Kapusniak, J. (2016). Utilization of starch films plasticized with urea as fertilizer for improvement of plant growth. Carbohydrate Polymers, 137, 127-138. https://doi.org/10.1016/j.carbpol.2015.10.051 
Shaw, R. J. (1999). Soil salinity—Electrical conductivity and chloride. In K. I. Peverill, L. A. Sparrow, \& D. J. Reuter (Eds.), Soil analysis: An interpretation manual (pp. 129-144). Melboune: CSIRO Publishing.

Trenkel, M. E. (2010). Slow and Controlled Release and Stabilized Fertilizers: An Option for Enhancing Nutrient Use Efficiency in Agriculture. International Fertilizer Industry Association, Paris, France.

von Uexkull, H. R., \& Fairhurst, T. H. (1991). Fertilizer for High Yield and Quality: The Oil Palm. International Potash Institute. Burn, Switzerland.

Wada, G., Aragones, R. C., \& Ando, H. (1991). Effect of slow release fertilizer (Meister) on the nitrogen uptake and yield of the rice plant in the tropics. Japan Jour. Crop Sci., 60(1), 101-106. https://doi.org/10.1626/ jcs.60.101

Yan, D., \& Zheng-yin, W. (2007). Release characteristics of different N forms in an uncoated slow/controlled release compound fertilizer. Agricultural Science in China, 6(3), 330-337. https://doi.org/10.1016/S16712927(07)60053-4

Yamamoto, C. F., Pereira, E. I., Mattoso, L. H. C., Matsunaka, T., \& Ribeiro, C. (2016). Slow release fertilizers based on urea/urea-formaldehyde polymer nanocomposites. Chemical Engineering Journal, 287, 390-397. https://doi.org/10.1016/j.cej.2015.11.023

\section{Copyrights}

Copyright for this article is retained by the author(s), with first publication rights granted to the journal.

This is an open-access article distributed under the terms and conditions of the Creative Commons Attribution license (http://creativecommons.org/licenses/by/4.0/). 